\title{
Terminal Imido Rhodium Complexes ${ }^{[* *]}$
}

\author{
Ana M. Geer, Cristina Tejel*, José A. López, and Miguel A. Ciriano**
}

\author{
Dedicated to Prof. Pablo Espinet on occasion of his 65 birthday
}

Abstract: Compounds of the late transition metals with multiple $M=X$ bonds $\left(X=C R_{2}, N R, O\right)$ represent a synthetic challenge, partly overcome by preparative chemists, but with noticeable lacks in the second and third rows. For example, there are no isolated examples of terminal imido rhodium complexes known to date. Here, we showcase the isolation, characterization, and some preliminary reactivity studies of the first rhodium complexes $\left[R h\left(\mathrm{PhBP}_{3}\right)(\mathrm{NR})\right]$ $\left(\mathrm{PhBP}_{3}=\mathrm{PhB}\left\{\mathrm{CH}_{2} \mathrm{PPh}_{2}\right\}_{3}\right)$ with a multiple and terminal $\mathrm{Rh}=\mathrm{N}$ bond. These imidos result from reactions of organic azides with the corresponding rhodium(I) complex having a labile ligand, and display a pseudo-tetrahedral core geometry with an almost linear $\mathrm{Rh}-\mathrm{N}-\mathrm{C}$ arrangement (177.5(2) $\left.{ }^{\circ}\right)$ and a short $\mathrm{Rh}-\mathrm{N}$ bond (1.780(2) $\AA$ ). We also show that the $R h=N$ bond undergoes protonation at nitrogen or addition of $\mathrm{H}_{2}$, as well as can engage in nitrene group transfer and cycloaddition reactions.

Complexes with a terminal imido functionality bound to a single late transition metal center (Groups 8-11) are or have been proposed as intermediates in novel $\mathrm{C}-\mathrm{H}$ bond functionalization reactions such as amination and aziridination through the use of $\mathrm{N}$-atom transfer protocols, ${ }^{[1]}$ and yet the isolated of such compounds still remain relatively uncommon. ${ }^{[2]}$ The lack of characterization of such active intermediates that can mediate catalytic $\mathrm{C}-\mathrm{N}$ bond formation is rather unfortunate, and claims for a fundamental understanding of metal-imido or metal-nitrene species are warranted. Unfortunately, the preparation of such interesting species can be difficult, especially when such system can participate in reactions such as $\mathrm{H}-$ atom transfer reactions involving aliphatic $\mathrm{C}-\mathrm{H}$ bonds. ${ }^{[3]}$

The high $\mathrm{p} \pi$ electron loading of the imido group renders multiple bond character and strong $\mathrm{M}=\mathrm{N}$ bonds possible for metals with low $\mathrm{d}^{\mathrm{n}}$ electron counts, i.e., for early transition metals and high oxidation states, but destabilizes the interaction with late transition metals in tetragonal structures with filled $\mathrm{d} \pi$ orbitals. $^{[4]}$ This typically makes their isolation difficult. However, the use of lowcoordinate architectures that possess empty $\mathrm{d} \pi$ metal orbitals has enabled various groups to uncover the synthesis and reactions of a number of terminal imido complexes of cobalt ${ }^{[5]}$ and nickel ${ }^{[1 \mathrm{e}],[6]}$ with geometries ranging from pseudo-tetrahedral, trigonal-planar and even linear structures, and with $\mathrm{d}^{6}$ to $\mathrm{d}^{8}$ configurations. Specifically, when moving to the heavier congeners of group 9 ,

[*] A. M. Geer, Dr. C. Tejel, Dr. J. A. López, Prof. M. A. Ciriano Departamento de Química Inorgánica Instituto de Síntesis Química y Catálisis Homogénea (ISQCH), CSIC - Universidad de Zaragoza Pedro Cerbuna 12, 50009-Zaragoza (Spain) Fax: (+) 34976761187 E-mail: ctejel@unizar.es; mciriano@unizar.es

[**] The generous financial support from MICINN/FEDER (Project CTQ2011-22516) and Gobierno de Aragón/FSE (GA/FSE, Inorganic Molecular Architecture Group, E70), are gratefully acknowledged. A. M. Geer thanks G.A. for a fellowship.

Supporting information for this article is available on the WWW under http://www.angewandte.org or from the author.
Bergman's Ir imido complexes with the general formula $\mathrm{Cp} * \mathrm{Ir} \equiv \mathrm{NR}$ $(\mathrm{R}=\text { aryl, alkyl, silyl })^{[7]}$ still stand as the sole structurally characterized compound with a terminal imido ligand. Surprisingly, rhodium, ${ }^{[8]}$ the link between Co and Ir, has yet to show tendency to stabilize a terminal imido ligand.

Indirect evidence for the existence of a transient imido complex $\left[\left(\mathrm{C}_{5} \mathrm{Me}_{5}\right) \mathrm{RhNR}\right]\left(\mathrm{R}=2,6-{ }^{i} \mathrm{Pr}_{2} \mathrm{C}_{6} \mathrm{H}_{3}\right)$ was obtained from the isolation of the tetrazene $\left[\left(\mathrm{C}_{5} \mathrm{Me}_{5}\right) \mathrm{Rh}\left(\mathrm{mesN}_{4} \mathrm{R}\right)\right]$ as a result of the condensation of the species generated in situ with $\operatorname{mesN}_{3} \cdot{ }^{[9]}$ Unfortunately, the related dinuclear complex $\left[\left\{\left(\mathrm{C}_{5} \mathrm{Me}_{5}\right) \mathrm{Rh}(\mu\right.\right.$ NTs) $\}_{2}$ ] yields also the same type of product. ${ }^{[10]}$ Other examples of rhodium imidos were reported by McGlinchey and Stone, but such species have been ill-characterized. ${ }^{[11]}$ As a result, just two families of $\mathrm{d}^{8}$-rhodium imido complexes are known, namely, the dinuclear dppm-bridged amido/imido tautomers, ${ }^{[12]}$ and polynuclear complexes based on triply bridging " $\mu_{3}-\mathrm{NC}_{6} \mathrm{H}_{4} \mathrm{Me}$ " imido ligands. ${ }^{[13]}$ More recently, a related $\mathrm{Rh}(\mathrm{II})$ complex with a single imido group bridging the metal-metal bond has been reported. ${ }^{[14]}$

Our initial attempts to isolate imido compounds from reactions of $\mathrm{Rh}$ (III) complexes via deprotonation of coordinated amines, as reported by Danopoulos and Wilkinson, ${ }^{[9]}$ were unsuccessful. We then hypothesized whether a low-coordinate precursor was required to generate imido species with a multiple $\mathrm{N}=\mathrm{Rh}$ bond through oxidation. For this reason, we focused our attention on the fac$\mathrm{Rh}\left[\mathrm{PhBP}_{3}\right]$ fragment, as highlighted by Peters with iron and cobalt $\left(\mathrm{PhBP}_{3}=\mathrm{PhB}\left\{\mathrm{CH}_{2} \mathrm{PPh}_{2}\right\}_{3}\right) .{ }^{[\mathrm{a}]}$ Herein we report the successful synthesis and full characterization of the first rhodium complexes bearing a terminal imido ligand and also report some exploratory reactions involving the $\mathrm{Rh}=\mathrm{N}$ multiple bond.

We chose a relatively bulky adamantyl azide as a nitrene source by reaction with the complex $\left[\mathrm{Rh}\left(\mathrm{PhBP}_{3}\right)\left(\mathrm{C}_{2} \mathrm{H}_{4}\right)(\mathrm{NCMe})\right](\mathbf{1}) .{ }^{[15]}$ Upon addition and warming of the solution in toluene a slow change of color from yellow to brown was observed, which yielded the imido complex $\left[\mathrm{Rh}\left(\mathrm{PhBP}_{3}\right)(\mathrm{NAd})\right]$ (2) as amber-like crystals after subsequent workup. No intermediates were observed when the reaction was monitored by NMR spectroscopy $\left({ }^{1} \mathrm{H},{ }^{31} \mathrm{P} ; \mathrm{C}_{6} \mathrm{D}_{6}\right)$. Aromatic azides react also with $\mathbf{1}$ in toluene to yield purple solutions of the corresponding imido complexes $\left[\mathrm{Rh}\left(\mathrm{PhBP}_{3}\right)(\mathrm{NR})\right](\mathrm{R}=2,6$ $\left.{ }^{i} \mathrm{Pr}_{2} \mathrm{C}_{6} \mathrm{H}_{3}(\mathbf{3}), \quad \mathrm{C}_{6} \mathrm{~F}_{5}(\mathbf{4})\right)$. Complex 3 was isolated as a purple microcrystalline solid, while $\mathbf{4}$ was characterized in situ.

For complex 2, we were fortunate to obtain reliable X-ray diffraction data of a single crystal, ${ }^{[16]}$ and the structure revealed a rhodium atom confined in an almost perfect tetrahedral with overall $C_{3 \mathrm{v}}$ symmetry due to its bonding to three equivalent phosphorus atoms of the tripodal $\mathrm{PhBP}_{3}$. The fourth site is represented by the imido ligand, having a $\mathrm{Rh}-\mathrm{N}_{\text {imido }}$ bond distance $(1.780(2) \AA)$ that is short by about $0.3 \AA$ when compared to similar species having bridging amido or imido ligands, ${ }^{[10],[13],[17]}$ but similar to that observed for $[\mathrm{IrCp} * \mathrm{NR}]{ }^{[7]}$ The short distance together with an almost linear $\mathrm{Rh}-\mathrm{N}_{\text {imido }}-\mathrm{C}_{\mathrm{Ad}}$ angle $\left(177.5(2)^{\circ}\right)$ are indicative of such ligand having multiple $\mathrm{Rh}-\mathrm{N}$ bond character. Although the adamantyl group was found to be disordered in two positions and these were modelled, for the purpose of clarity we display only one as shown in Figure 1. 


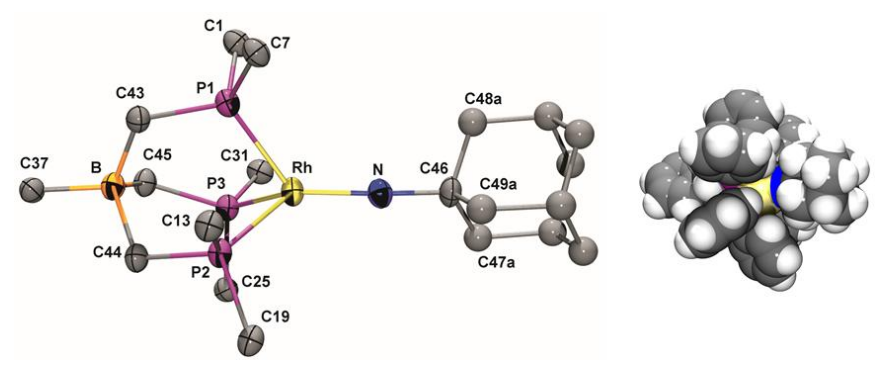

Figure 1. Left: structure (ORTEP at $50 \%$ level) of complex [Rh( $\left.\left.\mathrm{PhBP}_{3}\right) \mathrm{NAd}\right]$ (2) (only the $\mathrm{C}^{\text {ipso }}$ atoms of the phenyl groups from $\mathrm{PPh}_{2}$ are shown for clarity) (left). Selected bond distances $(\AA)$ angles (): Rh-P1, 2.2629(7); Rh-P2, 2.2839(7); Rh-P3, 2.2591(7); Rh-N, 1.780(2); N-C46, 1.431(3); P1-Rh-N, 127.83(8); P2-Rh-N, 127.51(7); P3-Rh-N, 126.39(8); axis(B,Rh)-N, 179.59(9). Rh-N-C46, 177.5(2). Right: Space filling representation of complex 2.

Repetitive attempts to grow up single crystals of complexes $\mathbf{3}$ or 4 gave systematically very small and geminated microcrystals, preventing crystallographic structure determination. Nonetheless, complexes 2-4 display a characteristic doublet $\left(J_{\mathrm{P}, \mathrm{Rh}} \approx 110 \mathrm{~Hz}\right)$ in the ${ }^{31} \mathrm{P}\left\{{ }^{1} \mathrm{H}\right\}$ NMR spectra distinctive of species of high symmetry, as shown by the structure of $\mathbf{2}$. All of them possess identical connectivity, which is clearly detected by the couplings of the phosphorus nuclei with carbon, proton, or fluorine nuclei of the groups $\mathrm{R}$ bonded to the imido nitrogen. Moreover, their hydrodynamic radii $\left(\mathrm{r}_{\mathrm{H}}\right)$, evaluated by DOSY experiments, exhibit similar values $(6.84,6.69$, and $6.36 \AA$, for $\mathbf{2}, \mathbf{3}$, and $\mathbf{4}$, respectively), which evidences that they are mononuclear in solution and exclude plausible monomer/dimer equilibria. Furthermore, these radii are close to the averaged molecular ones calculated by DFT methods (7.07 and $6.74 \AA$, for $\mathbf{2 a}$ and $\mathbf{4 a}$, respectively).

Complexes 2-4 are thermally stable, but highly sensitive to moisture, being 2 the least sensitive. Their solutions in $\mathrm{C}_{6} \mathrm{D}_{6}$ are immediately hydrolyzed by traces of water giving the free amine and uncharacterized beige solids insoluble in common organic solvents. Hence, the imido nitrogen is a Brønsted base that abstracts protons from water. In this sense, complex 2 reacts cleanly with protic acids such as $\mathrm{HBF}_{4} \cdot \mathrm{Et}_{2} \mathrm{O}$ ( 2 molar-equiv) in acetonitrile to give the amine $\mathrm{H}_{2} \mathrm{NAd}$ and $\left[\mathrm{Rh}\left(\mathrm{PhBP}_{3}\right)(\mathrm{NCMe})_{3}\right]\left(\mathrm{BF}_{4}\right)_{2}{ }^{[15]}$ No other compounds except the starting complex were observed in this reaction when using a 1:1 molar ratio.

To gain insight into the electronic structure of complexes 2-4 and the characteristics of the Rh-N bond, DFT calculations [b3lyp, LanL2Tz(f)/6-311G(d)/6-31G(d,p)] were carried out on complexes $\left[\mathrm{Rh}\left(\mathrm{PhBP}_{3}\right)(\mathrm{NR})\right]\left(\mathrm{R}=\mathrm{Ad}(\mathbf{2 a}), \mathrm{C}_{6} \mathrm{~F}_{5}(\mathbf{4 a})\right)$ and on a model compound of $\mathbf{3}$ (3a), in which the ${ }^{i} \mathrm{Pr}$ substituents on the imido aryl were replaced by hydrogen. The results of the calculation for $\mathbf{2 a}$ give geometrical parameters that are in good agreement with the experimentally determined structure of 2 (Figure S4 and Table S1). For the aryl imido complexes $\mathbf{3 a}$ and $\mathbf{4 a}$, the symmetry of the calculated structure is lowered away from $C_{3}$ by distortion of the metal coordination sphere. An off-axis distortion in which the Rh-N vector is bent away from the $\mathrm{B}-\mathrm{C}$ vector gives rise to a core slightly distorted towards a trigonal pyramid. In addition, the $\mathrm{Rh}-\mathrm{N}-\mathrm{C}$ angles $\left(166.73^{\circ}, 170.68^{\circ}\right.$, respectively) are more bent than for the alkylimido 2 , which is typical for arylimido complexes. ${ }^{[4 b, 18]}$ The ground-state frontier MOs diagram for 2a is shown in Figure 2. The LUMO and LUMO+1 correspond to two antibonding combinations of the metal-based orbitals $2 \mathrm{e}_{\mathrm{a}}$ and $2 \mathrm{e}_{\mathrm{s}}$ (of parentage $\mathrm{d}_{\mathrm{xz}}$ and $\mathrm{d}_{\mathrm{yz}}$ ) with the $p_{x}$ and $p_{y}$ orbitals of the imido nitrogen. The respective bonding combinations, HOMO-39 and HOMO-40, are found lower in energy, so that they correspond to two $\mathrm{Rh}-\mathrm{N} \pi$-bonds. The $\sigma$ component mainly arises from the overlap between the filled $\mathrm{d}_{\mathrm{z}}{ }^{2}$ orbital $\left(1 \mathrm{a}_{1}\right)$ with a filled sp orbital of the nitrogen, as observed in HOMO-2 and HOMO-63. Under this perspective, the $\mathrm{Rh}-\mathrm{N}$ bond would lack the $\sigma$-component, hence more in accord with a double bond. Nonetheless, the topology of the $\mathrm{d}_{\mathrm{z}}{ }^{2}$-based MOs clearly suggests a further mixing with the empty low-lying $2 \mathrm{a}_{1}$ orbital of the $\left[\mathrm{Rh}\left(\mathrm{PhBP}_{3}\right)\right]^{2+}$ fragment (see inset in Figure 2). This symmetryallowed mixing stabilizes the $\mathrm{dz}^{2}$ orbital, mitigating the destabilizing effect of populating the $\mathrm{Rh}-\mathrm{N} \sigma^{*}$ interaction. Moreover, the measured metrical parameters imply that the $\mathrm{Rh}-\mathrm{N}$ bond should actually be considered close to a triple bond according to the bond distance computed for a $\mathrm{Rh}-\mathrm{N}$ triple bond, $1.80 \AA$, using the method put forth by Pauling. ${ }^{[19]}$ On the whole, the bonding in this imido complex seems to be similar to that of pseudo-tetrahedral cobalt(III) imido complexes with tripodal ligands. ${ }^{[4 b],[5 a-f]}$

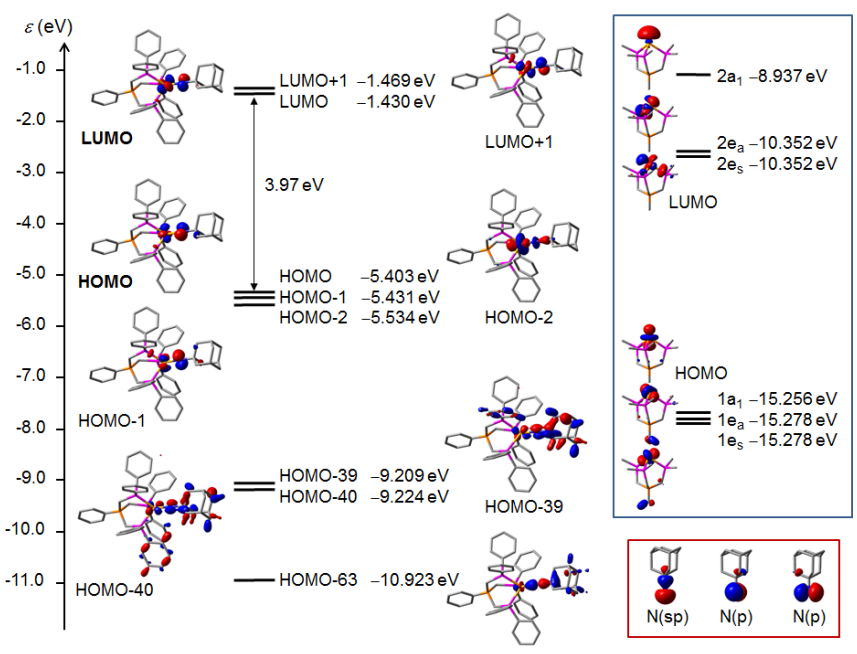

Figure 2. Frontier MOs energy level diagram for complex 2a showing relevant MOs involved in the multiple $\mathrm{Rh}=\mathrm{N}$ bond. The blue inset shows the frontier MOs for the fragment $\left[\mathrm{Rh}\left(\mathrm{PhBP}_{3}\right)\right]^{2+}$, while the red inset display those of the NAd fragment involved in the $\mathrm{Rh}=\mathrm{N}$ bond.

Similar computed MO diagrams result for complexes $\mathbf{3 a}$ and $\mathbf{4 a}$, but the relevant MOs are not degenerate and the HOMO-LUMO gap (3.00 eV for 3a and 4a) is smaller than for 2a. In addition, although the natural charge of the Rh atom from a NBO analysis of $\mathbf{2 a - 4 a}$ is quite similar $(\approx 0.120)$, this is highly negative and noticeably larger for the nitrogen atom in $\mathbf{4 a}(-0.7711)$ than in $\mathbf{3 a}(-0.7018)$ and $\mathbf{2 a}$ $(-0.6983)$, which is indicative of a more polar $\mathrm{Rh}=\mathrm{N}$ bond in $\mathbf{4 a}$. Both data are consistent with the experimental grade of reactivity of complexes: $\mathbf{4 a}>\mathbf{3 a}>\mathbf{2 a}$ (vide infra).

We explored the reactivity of these imidos. Accordingly, group transfer of the imido functionality in $\mathbf{2}$ occurred in the presence of excess $\mathrm{CO}$ to form $\left[\mathrm{Rh}\left(\mathrm{PhBP}_{3}\right)(\mathrm{CO})_{2}\right]^{[20]}$ and the isocyanate AdNCO in 16 hours (Scheme 1). A similar, but much faster reaction occurs when treating complex $\mathbf{3}$ with $\mathrm{CO}$, which was completed in a matter of minutes to produce the same rhodium carbonyl complex and the isocyanate, 2,6- ${ }^{i} \mathrm{Pr}_{2} \mathrm{C}_{6} \mathrm{H}_{3} \mathrm{NCO}$. Both isocyanates were characterized by their characteristic $v(\mathrm{NCO})$ IR band between 2300 and $2250 \mathrm{~cm}^{-1}$ and ${ }^{1} \mathrm{H}$ NMR spectra. Related imide carbonylations are known for several late transition metal imides. ${ }^{[7],[21]}$ 


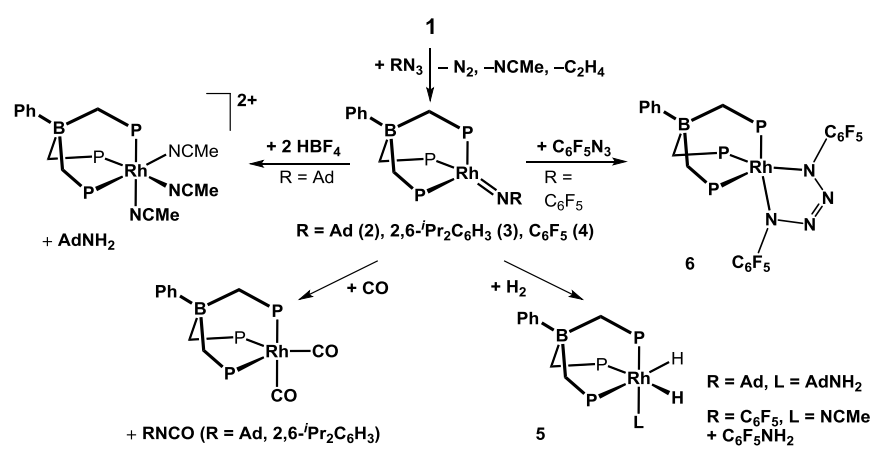

Scheme 1. Synthesis and reactions of complexes 2-4.

In more unique reactions, exposure of a $\mathrm{C}_{6} \mathrm{D}_{6}$ solution of $\mathbf{2}$ or $\mathbf{4}$ to 5 atm of $\mathrm{H}_{2}$ at $23{ }^{\circ} \mathrm{C}$ resulted in hydrogenation of the $\mathrm{Rh}=\mathrm{NR}$ linkage to yield the dihydride rhodium complexes $\left[\mathrm{Rh}\left(\mathrm{PhBP}_{3}\right)(\mathrm{H})_{2}\left(\mathrm{H}_{2} \mathrm{NAd}\right)\right] \quad(\mathbf{5})$ and $\left[\mathrm{Rh}\left(\mathrm{PhBP}_{3}\right)(\mathrm{H})_{2}(\mathrm{NCMe})\right],{ }^{[15]}$ respectively, which were characterized by NMR spectroscopic methods. The reaction is very slow for $\mathbf{2}$ at room temperature taking five days to reach completion, while for $\mathbf{4}$ the hydrogenation is complete in $30 \mathrm{~min}$. No diamagnetic intermediates were observed on monitoring the reactions by ${ }^{1} \mathrm{H}$ and ${ }^{31} \mathrm{P}$ NMR spectroscopy. Since the metal is electrophilic, as shown by the previous reaction and the $\mathrm{Rh}$ positive charge while the nitrogen supports a negative charge, most probably hydrogen adds to the multiple $\mathrm{Rh}=\mathrm{N}$ bond in a heterolytic way to produce an unobserved pentacoordinated amidohydride complex of formula $\left[\mathrm{Rh}\left(\mathrm{PhBP}_{3}\right) \mathrm{H}(\mathrm{NHR})\right]$, which adds a second molecule of dihydrogen to render the amine-dihydride complexes. Since no intermediates are observed, we propose the first step to be slow en route to the final product. While the amine $\mathrm{AdNH}_{2}$ remains coordinated in $\mathbf{5}$, free amine $\mathrm{C}_{6} \mathrm{~F}_{5} \mathrm{NH}_{2}$ was found at the end of the reaction of $\mathbf{4}$, as the result of the displacement by acetonitrile present in the reaction medium.

Complex $\mathbf{2}$ is sluggishly reactive and does not further transform with the azides $\mathrm{N}_{3} \mathrm{Ad}$, and $\mathrm{N}_{3} \mathrm{C}_{6} \mathrm{~F}_{5}$. However complex 4 is so reactive that it reacts immediately with $\mathrm{N}_{3} \mathrm{C}_{6} \mathrm{~F}_{5}$ to give the tetrazene complex $\left[\mathrm{Rh}\left(\mathrm{PhBP}_{3}\right)\left\{\mathrm{N}_{4}\left(\mathrm{C}_{6} \mathrm{~F}_{5}\right)_{2}\right\}\right]$ (6). The synthesis of tetrazene complexes from organic azides and low-valent metal precursors is well-precedented, ${ }^{[22]}$ although examples of rhodium tetrazene complexes are quite scarce. In the solid state structure of complex $\mathbf{6}$, the $\mathrm{C}_{6} \mathrm{~F}_{5}$ groups are placed at the 1,4-positions of the tetrazene, which is consistent with a dipolar 1,3-cycloaddition of the azide to the $\mathrm{Rh}=\mathrm{N}$ bond (Scheme 1). Thus, the mechanism follows that proposed in the synthesis of tetrazenes from organic azides and isolated or transient metal-imido intermediates. ${ }^{[22]}$ Also in the structure of 6 (Figure 3) the rhodium atom displays a distorted trigonal bipyramid environment, as a result of being gripped by the tripodal $\mathrm{PhBP}_{3}$ and chelating $\mathrm{N}_{4}\left(\mathrm{C}_{6} \mathrm{~F}_{5}\right)_{2}$ ligands. The three Rh-P bond distances were found to be different, with the $\mathrm{P}$-atom at the apical position (P3) being the longest. Both $\mathrm{Rh}-\mathrm{N}$ bond distances are in the range of typical single $\mathrm{Rh}-\mathrm{N}$ bonds with the equatorial one (Rh-N1) being the shortest. Within the tetrazene ligand, the central N2-N3 bond distance is close to that of a double $\mathrm{N}=\mathrm{N}$ bond while N1-N2 and N3-N4 bond distances are smaller than those of single $\mathrm{N}-\mathrm{N}$ bonds. These short distances and the strictly planar ' $\mathrm{RhN}_{4}$ ' metallacycle (maximum deviation for the plane $0.012 \AA$ ) indicate a delocalization in the ring. Accordingly, a major contribution to the electronic structure of $\mathbf{6}$ arises from the canonic form $\left[\mathrm{Rh}^{\mathrm{III}}\left\{\left(\mathrm{C}_{6} \mathrm{~F}_{5}\right)_{2} \mathrm{~N}_{4}\right\}^{2-}\right]$ with a dianionic tetrazenide ligand, but the metal environment geometry and the $\mathrm{N}-\mathrm{N}$ bond distances stand for a non-negligible representation of the tetrazadiene- $\mathrm{Rh}(\mathrm{I})$ form.

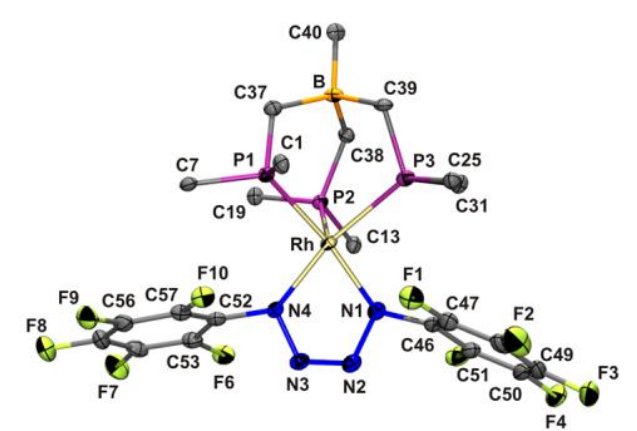

Figure 3. Structure (ORTEP at $50 \%$ level) of complex $\left[R h\left(\mathrm{PhBP}_{3}\right)\left\{\mathrm{N}_{4}\left(\mathrm{C}_{6} \mathrm{~F}_{5}\right)_{2}\right\}\right]$ (6) (only the $\mathrm{C}^{\text {ipso }}$ atoms of the phenyl groups from $\mathrm{PPh}_{2}$ are shown for clarity). Selected bond distances $(\AA)$ and angles (ㅇ): Rh-P1, 2.3168(8); Rh-P2, 2.2926(9); Rh-P3, 2.4081(9); $\mathrm{Rh}-\mathrm{N} 1,2.008(3) ; \mathrm{Rh}-\mathrm{N} 4,2.053(3) ; \mathrm{N} 1-\mathrm{N} 2,1.397(4), \mathrm{N} 2-\mathrm{N} 3$, 1.259(4); N3-N4 1.371(4); P3-Rh-N4, 166.41(8); P1-Rh-N1, 149.76(8); P2-Rh-N1, 123.34(8); P1-Rh-P2, 86.83(3); N1-Rh-N4, 74.0(1); Rh-N1-N2, 118.0(2); N1-N2-N3, 114.3(3); N2-N3-N4, 116.4(3); N3-N4-Rh, 116.3(2).

The difference in reactivity of the aryl $(\mathbf{3}, \mathbf{4})$ versus the alkyl (2) imido complexes is not only determined by the electronic structure of these complexes but also by their kinetics. The $\mathrm{Rh}-\mathrm{N}$ bond is protected in same way by the steric encumbrance provided by the phenyl groups of the tripod ligand, which encircle it with the planes almost aligned in the direction of the bond (see Figure 2 right). Presumably, the bent arrangement of the imido ligand in $\mathbf{3}$ and $\mathbf{4}$ and the reduced bulkiness of the aryl versus adamantyl groups permit the access to a wider array of substrates at the rhodium-imido bond.

Moreover, the bulkiness of the $\mathrm{PhBP}_{3}$ ligand along with that of the adamantly group on the nitrogen avoid the formation of a dimer of the type $\left[\left\{\mathrm{Rh}\left(\mathrm{PhBP}_{3}\right)(\mu-\mathrm{NR})\right\}_{2}\right]$. Further, even for the smaller $\mathrm{C}_{6} \mathrm{~F}_{5}$ group, DFT calculations show the dimer to be very congested in the region between the rhodium atoms and $17.9 \mathrm{kcal} \mathrm{mol}^{-1}$ higher in enthalpy than the monomer (see Supporting Information), which also corroborates these rhodium-imido complexes are mononuclear.

In summary, the first rhodium complexes containing terminal alkyl and aryl imido ligands have been prepared and characterized. These compounds are thermally stable and diamagnetic and the solid-state structure for an alkyl-imido derivative displays a linear $\mathrm{Rh}-\mathrm{N}-\mathrm{C}$ linkage with a short Rh-N distance whereby the metal ion is confined in a pseudo-tetrahedral environment. ${ }^{[23]}$ These characteristics are a consequence of a special and multiple $\mathrm{Rh}=\mathrm{N}$ bond consisting primarily in two $\mathrm{Rh}-\mathrm{N} \pi$-bonds. Our findings fill a gap in the chemistry of Group 9 metals. Preliminary studies indicate that rhodium imides are somewhat ambiphilic and can therefore undergo protonation at nitrogen as well as hydrogenation at the $\mathrm{Rh}=\mathrm{N}$ bond. These systems also engage in nitrene group transfer, and cycloaddition reactions, although their reactivity is strongly modulated by the organic group bound to nitrogen.

Received: ((will be filled in by the editorial staff))

Published online on ((will be filled in by the editorial staff))

Keywords: terminal imido $\cdot$ rhodium $\cdot$ multiple $\mathrm{M}=\mathrm{N}$ bond $\cdot$ azides . group transfer · dipolar 1,3-cycloaddition.

[1] For recent leading references see for example: a) J. L. Roizen, M. E. Harvey, J. Du Bois, Acc. Chem Res. 2012, 45, 911-922; b) Q. Nguyen, K. Sun, T. G. Driver, J. Am. Chem. Soc. 2012, 134, 7262-7265; c) S. Wiese, J. L. McAfee, D. R. Pahls, C. L. McMullin, T. R. Cundari, T. 
H. Warren, J. Am. Chem. Soc. 2012, 134, 10114-10121; d) T. A. Ramirez, B. Zhao, Y, Shi, Chem. Soc. Rev. 2012, 41, 931-942; e) C. A. Laskowski, A. J. M. Miller, G. L. Hillhouse, T. R. Cundari, J. Am. Chem. Soc. 2011, 133, 771-773; f) F. Collet, C. Lescot, P. Dauban, Chem. Soc. Rev. 2011, 40, 1926-1936; g) H. M. L. Davies, J. R. Manning, Nature 2008, 451, 417-424; h) Y. M. Badiei, A. Dinescu, X Dai, R. M. Palomino, F. W. Heinemann, T. R. Cundari, T. H. Warren, Angew. Chem. 2008, 120, 10109-10112; Angew. Chem. Int. Ed. 2008, 47, 9961-9964; i) P. Muller, C. Fruit, Chem. Rev. 2003, 103, 2905$2920 ;$ j)

, J. Am. Chem. Soc. 2013, 135, 1338-1348. k) A I. Olivos Suarez, H. Jiang, X. P. Zhang, B. de Bruin, Dalton Trans. 2011, 40, 5697-5705.

[2] J. F. Berry, Comments Inorg. Chem. 2009, 30, 28-66.

[3] a) E. R. King, E. T. Hennessy, T. A. Betley, J. Am. Chem. Soc. 2011 133, 4917-4923; b) E. T. Hennessy, T. A. Betley, Science 2013, 340 591-595; c) A. I. Olivos Suarez, V. Lyaskovskyy, J. N. H. Reek, J. I. van der Vlugt, B. de Bruin, Angew. Chem. 2013, 125, 12740-12760 Angew. Chem. Int. Ed. 2014, 52, 12510-12529. d) V. Lyaskovskyy, A. I. Olivos Suárez, H. Lu, H. Jiang, X. P. Zhang, B. de Bruin, J. Am. Chem. Soc. 2011, 133,12264-12273.

[4] a) C. T. Saouma, J. C. Peters, Coord. Chem. Rev. 2011, 255, 920-937; b) I. H. Wasbotten, A. Ghosh, Inorg. Chem. 2007, 46, 7890-7898, c) W. A. Nugent, J. M. Mayer, Metal-Ligand Multiple Bonds, Wiley, New York, 1988.

[5] a) D. M Jenkins, T. A. Betley, J. C. Peters, J. Am. Chem. Soc. 2002, 124, 11238-11239; b) T. A. Betley, J. C. Peters, J. Am. Chem. Soc. 2003, 125, 10782-10783; c) X. Dai, P. Kapoor, T. H. Warren, J. Am. Chem. Soc. 2004, 126, 4798-4799; d) X. Hu, K. Meyer, J. Am. Chem. Soc. 2004, 126, 16322-16323. e) D. T. Shay, G. P. A. Yap, L. N. Zakharov, A. L. Rheingold, K. H. Theopold, Angew. Chem. 2005, 117, 1532-1534; Angew. Chem. Int. Ed. 2005, 44, 1508-1510; f) R. E. Cowley, R. P. Bontchev, J. Sorrell, O. Sarracino, Y. Feng, H. Wang, J. M. Smith, J. Am. Chem. Soc. 2007, 129, 2424-2425; g) C. Jones, C. Schulten, R. P. Rose, A. Stasch, S. Aldridge, W. D. Woodul, K. S. Murray, B. Moubaraki, M. Brynda, G. La Macchia, L. Gagliardi, Angew. Chem. 2009, 121, 7542-7546; Angew. Chem. Int. Ed. 2009 48, 7406-7410; h) E. R. King, G. T. Sazama, T. A. Betley, J. Am. Chem. Soc. 2012, 134, 17858-717861.

[6] a) D. J. Mindiola, G. L. Hillhouse, J. Am. Chem. Soc. 2001, 123, 4623-4624; b) R. Waterman, G. L. Hillhouse J. Am. Chem. Soc. 2003 125, 13350-13351; c) E. Kogut, H. L. Wiencko, L. Zhang, D. E. Cordeau, T. H. Warren, J. Am. Chem. Soc. 2005, 127, 11248-11249; d) R. Waterman, G. L. Hillhouse J. Am. Chem. Soc. 2008, 130, 12628-12629; e) N. D. Harrold, R. Waterman, G. L. Hillhouse, T. R. Cundari, J. Am. Chem. Soc. 2009, 131, 12872-12873; f) V. M. Iluc, A. J. M. Miller, J. S. Anderson, M. J. Monreal, M. P. Mehn, G. L. Hillhouse, J. Am. Chem. Soc. 2011, 133, 13055-13063; g) S. Wiese, J. L. McAfee, D. R. Pahls, C. L. McMullin, T. R. Cundari, T. H. Warren, J. Am. Chem. Soc. 2012, 134, 10114-10121.

[7] D. S. Glueck, J. Wu, F. J. Hollander, R. G. Bergman, J. Am. Chem. Soc. 1991, 113, 2041-2054.

[8] A transient terminal nitrido complex of rhodium, characterized spectroscopically, is the single example of multiple $\mathrm{Rh}=\mathrm{N}$ bonds. $\mathrm{M}$.
G. Scheibel, Y. Wu, A. C. Stückl, L. Krause, E. Carl, D. Stalke, B. de Bruin, S. Schneider, J. Am. Chem. Soc. 2013, 135, 17719-17722.

[9] A. A. Danopoulos, G. Wilkinson, T. K. N. Sweet, B. Hursthouse, J. Chem. Soc, Dalton Trans. 1996, 3771-3778.

[10] a) C. Tejel, M. A. Ciriano, S. Jiménez, V. Passarelli, J. A. López, Inorg. Chem. 2008, 47, 10220-10222; b) K. Ishiwata, S. Kuwata, T. Ikariya, J. Am. Chem. Soc. 2009, 131, 5001-5009; c) S. Takemoto, S. Otsuki, Y. Hashimoto, K. Kamikawa, H. Matsuzaka, J. Am. Chem. Soc. 2008, 130, 8904-8905.

[11] M. J. McGlinchey, F. G. A. Stone, Chem. Commun. 1970, 1265-1265.

[12] a) P. R. Sharp, J. Chem. Soc. Dalton Trans. 2000, 2647-2657; b) for a comprehensive list of references on bimetallic Group 9-11 complexes featuring bridging imido ligands see: R. E. Cowley, N. J. DeYonker, N. A. Eckert, T. R. Cundari, S. DeBeer, E. Bill, X. Ottenwaelder, C. Flaschenriem, P. L. Holland, Inorg. Chem. 2010, 49, 6172-6187.

[13] a) C. Tejel, M. A. Ciriano, M. Bordonaba, L. A. Oro, C. Graiff, A. Tirippicchio, Chem. Eur. J. 2004, 10, 708-715: b) C. Tejel, M. Bordonaba, M. A. Ciriano, F. J. Lahoz, L. A. Oro, Chem. Commun. 1999, 2387-2388; c) C. Tejel, Y. M. Shi, M. A. Ciriano, A. J. Edwards, F. J. Lahoz, J. Modrego, L. A. Oro, J. Am. Chem. Soc. 1997, 119, 6678-6679; d) C. Tejel, Y. M. Shi, M. A.Ciriano, A. J. Edwards, F. J. Lahoz, L. A. Oro, Angew. Chem. 1996, 108, 1614-1616; Angew. Chem. Int. Ed. 1996, 35, 1516-1518; e) C. Tejel, Y. M. Shi, M. A. Ciriano, A. J. Edwards, F. J. Lahoz, L. A. Oro, Angew. Chem. 1996, 108, 707-709; Angew. Chem. Int. Ed. 1996, 35, 633-634.

[14] S. Takemoto, S. Otsuki, Y. Hashimoto, K. Kamikawa, H. Matsuzaka, J. Am. Chem. Soc. 2008, 130, 8904-8905.

[15] C. Tejel, A. M. Geer, S. Jiménez, J. A. López, M. A. Ciriano, Organometallics 2012, 31, 2895-2906.

[16] CCDC 953092 (2) and 953741 (6) contains the supplementary crystallographic data for this paper. These data can be obtained free of charge from The Cambridge Crystallographic Data Centre via www.ccdc.cam.ac.uk/data request/cif.

[17] C. Tejel, M. A. Ciriano, M. Bordonaba, J. A. López, F. J. Lahoz, L. A. Oro, Chem. Eur. J. 2002, 8, 3128-3138.

[18] The angle Rh-N-C is very soft. Thus, an opening up to $180^{\circ}$ for $4 \mathbf{a}$ is associated to a low energy change of $0.3 \mathrm{kcal} \mathrm{mol}^{-1}$ (See Supporting Information).

[19] a) Pauling, L. The Nature of the Chemical Bond, 3rd ed.; Cornell University Press: Ithaca, NY, 1960; b) B. F. Wicker, H. Fan, A. K. Hickey, M. G. Crestani, J. Scott, M. Pink, D. J. Mindiola, J. Am. Chem. Soc. 2012, 134, 20081-20096.

[20] S. Jiménez, J. A. López, M. A. Ciriano, C. Tejel, A. Martínez, R. A. Sánchez-Delgado, Organometallics 2009, 28, 3193-3202.

[21] a) D. J. Mindiola, G. L. Hillhouse, Chem. Commun. 2002, 1840-1841; b) S. D. Brown, T. A. Betley, .J. C. Peters, J. Am. Chem. Soc. 2003, 125, 322-323; c) C. A. Laskowski, G. L. Hillhouse, Organometallics 2009, 28, 6114-6120.

[22] R. E. Cowley, E. Bill, F. Neese, W. W. Brennessel, P. L. Holland, Inorg. Chem. 2009, 48, 4828-4836, and references therein.

[23] A. M. Geer, A. Julián, J. A. López, M. A. Ciriano, C. Tejel, Chem. Eur. J. 2014, 20, 2732-2736. 


\section{Multiple Bonds}

Ana M. Geer, Cristina Tejel*, José A.

López, and Miguel A. Ciriano*

Page - Page

Terminal Imido Rhodium Complexes: A Missing Link

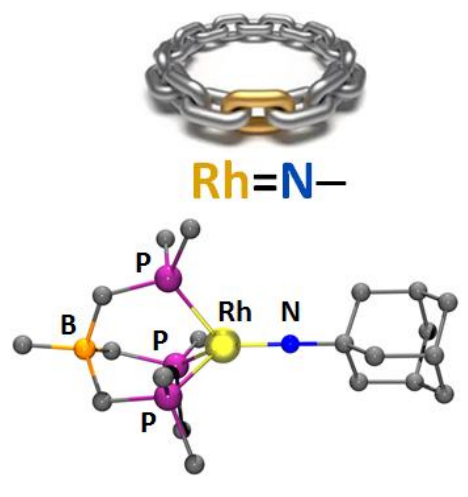

A missing link: Terminal imido rhodium complexes with a multiple $\mathrm{Rh}=\mathrm{N}$ bond have been prepared, providing thus a type of compound that has remained elusive to synthesis. The finding fills a gap in the chemistry of Group 9 metals. Preliminary studies indicate rhodium imides are somewhat ambiphilic and can therefore undergo protonation at nitrogen as well as hydrogenation at the $\mathrm{Rh}=\mathrm{N}$ bond. These systems also engage in nitrene group transfer and cycloaddition reactions. 